\title{
A História do Conceito de Função em Vídeo: uma proposta para a aprendizagem
}

\author{
The History of the Function Concept in Video: A Proposal for Learning
}

\author{
Paulo Roberto Castor Maciel* \\ Tereza Fachada Levy Cardoso ${ }^{* *}$
}

\begin{abstract}
Resumo
Esse trabalho propõe-se a promover uma aprendizagem significativa de função. Foi utilizada a História da Matemática como estratégia de ensino e o vídeo como recurso didático. A metodologia consistiu em pesquisa bibliográfica, criação de roteiro, pesquisa iconográfica, produção e edição de quatro vídeos e aplicação em sala de aula. Também foi construído um caderno de atividades para aprofundar a temática. Nas etapas relacionadas à construção dos vídeos, houve a participação de alunos de Ensino Médio. A intervenção foi realizada em uma turma de colégio estadual do Rio de Janeiro, do Ensino Médio. Como etapa prévia aos recursos didáticos, foi aplicada uma avaliação com questões objetivas com a finalidade de verificar o conhecimento acumulado. Após a exibição dos vídeos e resolução do caderno de atividades, aplicou-se uma segunda avaliação objetiva, de modo a comparar os resultados, que depois foram analisados. Concluiu-se avaliando o que manter ou modificar no trabalho desenvolvido.
\end{abstract}

Palavras-chave: Educação Matemática. Função. História da Matemática. Tecnologia Educacional.

\begin{abstract}
This paper is supposed to promote a significant function learning. It used The History of Mathematics as a learning strategy and the video as a didactic source. The methodology consisted of bibliographic research, screenplay guide, iconographic research, production and edition, and application in classroom. It is important to highlight that high school students participated during the phases related to the making of this video. An activity workbook was also developed to deepen the thematic. The intervention was made in a high school group class. As a previous stage to the didactic resources, an evaluation was applied with objective questions aiming at the verification of cumulative

\footnotetext{
* Mestre em Ensino de Ciências e Matemática pelo Centro Federal de Educação Tecnológica Celso Suckow (CEFET/RJ). Professor do Centro Universitário Serra dos Órgãos (UNIFESO), Rio de Janeiro, Rio de Janeiro, Brasil. Endereço para correspondência: Centro de Ciência e Tecnologia, Rua Gonçalo de Castro, número 85, Alto, CEP: 25960-090, Teresópolis/RJ, Brasil. E-mail: prcastor@ @otmail.com

** Doutora em História Social pela Universidade Federal do Rio de Janeiro (UFRJ). Professora do Mestrado em graduação, Avenida Maracanã, 229, sala E-502, Maracanã, CEP: 20271-110, Rio de Janeiro/RJ, Brasil. E-mail: tereza@levycardoso.com.br
} Ensino de Ciências e Matemática do Centro Federal de Educação Tecnológica Celso Suckow da Fonseca (CEFET/RJ), Rio de Janeiro, Rio de Janeiro, Brasil. Endereço para correspondência: Diretoria de Pesquisa e Pós-
\end{abstract}


knowledge. After the exhibition of the videos and the resolution of the activity workbook, a second objective evaluation was held as to compare the results which were later analyzed. We concluded evaluating what to keep in or edit the work developed.

Keywords: Education Mathematics. Function. History of Mathematics. Educacional Tecnology.

\section{Introdução}

A aprendizagem dos alunos tem sido um dos focos de pesquisas em Educação Matemática, como também de políticas públicas que visam à melhoria da educação. Propostas sobre a formação docente, utilização de novos recursos e metodologias para promover eficiência no processo de ensino vem crescendo nos últimos anos. Uma política governamental adotada para verificar se a aprendizagem tem alcançado um nível desejado é a utilização de testes de larga escala, como o Sistema Nacional de Avaliação da Educação Básica (SAEB) e o Sistema de Avaliação do Estado do Rio de Janeiro (SAERJ) - onde são quantificadas as habilidades de Língua Portuguesa e Matemática dos estudantes, com foco na leitura e resolução de problemas, respectivamente. A partir dos resultados das habilidades matemáticas, percebe-se que mais de $60 \%$ dos alunos não conseguem atingir o grau satisfatório nestas avaliações e estão nos níveis considerados baixo e intermediário (RIO DE JANEIRO, 2010). Tais provas avaliam as competências e habilidades adquiridas pelos estudantes, que constituem a Matriz de Referência que norteia a orientação curricular pertinente à disciplina e à série (BRASIL, 2008, p.17). Essa matriz nada mais é do que um recorte do currículo da disciplina, colocando em destaque as competências e habilidades.

Os itens da matriz referencial são definidos como descritores que "explicitam dois pontos básicos do que se pretende avaliar: o conteúdo programático e o nível de operação mental necessário para a aprendizagem" (RIO DE JANEIRO, 2008, p.20). Esses descritores estão divididos entre quatro temas: Espaço e Forma; Grandezas e Medidas; Números e Operações/ Álgebra e Funções; e Tratamento da Informação. Fazendo uma pequena análise dos descritores da Matriz Referencial para o ensino de Matemática, percebe-se a importância destinada ao conceito de função. Essa afirmação é respaldada no quantitativo de descritores, uma vez que representa mais de um terço do total, são 14 dos 35 relacionados com a temática em questão.

Para mudar o quadro de dificuldade na aprendizagem, é necessária a criação de um ensino que primeiro humanize a Matemática, que promova diálogo e significados sobre conceitos matemáticos, que os alunos possam compreender qual a importância de tal conceito para a 
sociedade em uma determinada época e compreender como ele está inserido na sociedade atual (BRASIL, 2000a).

Os Parâmetros Curriculares Nacionais (PCN) indicam quatro caminhos para se fazer Matemática na sala de aula. São eles: a) Resolução de Problemas; b) História da Matemática; c) Tecnologias da Informação e d) Jogos.

Sendo assim, percebe-se a necessidade de utilização de alguns desses caminhos na tentativa de melhorar a aprendizagem dos alunos. Para a realização desta investigação optou-se por dois: História da Matemática e Tecnologias da Informação.

A utilização da História da Matemática permite ao aluno desenvolver atitudes e valores favoráveis diante do conhecimento matemático, se forem mostradas as preocupações de diferentes culturas em momentos distintos e perceber a Matemática como uma criação dos homens que se deu a partir de suas necessidades (BRASIL, 2000a, p.45).

Já com relação à utilização de Tecnologias de Comunicação, pode-se afirmar que, em geral, contribuem para a melhoria do ensino da Matemática. Além disso, "é importante contemplar uma formação escolar nesses dois sentidos, ou seja, a Matemática como ferramenta para entender a tecnologia, e a tecnologia para entender a Matemática" (BRASIL, 2006, p.87). As tecnologias têm se tornado de fácil acesso e compra, o que tem popularizado a sua utilização, mas não se deve pensar que o seu uso não gera nenhum impacto, porque essa imersão em um mundo de tecnologias exige um processo de análise e reflexão por parte do educador. Dessa forma, a educação tem um papel importante ao se apropriar dessas tecnologias para a aprendizagem, o que, sem dúvida, acarreta um novo redimensionamento do ensino da Matemática do ponto de vista curricular, para o favorecimento do desenvolvimento de habilidades e procedimentos, onde $\mathrm{o}$ aluno poderá se reconhecer e se orientar no mundo em constante movimento.

O desenvolvimento da pesquisa, que aqui se apresenta em parte, gerou uma dissertação de mestrado, que visou promover uma aprendizagem significativa do conceito de função. Para isso, foi utilizada a história da ciência como estratégia de ensino e o vídeo como recurso. Dessa maneira, a História da Matemática precisou ser adequada ao ambiente escolar e aos estudantes do Ensino Básico, com o intuito de promover uma compreensão da matéria e torná-la atraente. Fezse uma pesquisa bibliográfica sobre o conceito, elaborou-se o roteiro, realizou-se também uma pesquisa iconográfica, foram feitas gravações das locuções e, então, iniciou-se a edição do vídeo. Após essas etapas, ocorreu a aplicação em sala de aula que compreendeu: exibição do vídeo, 
resolução do caderno de atividades e as avaliações diagnósticas. As etapas de criação do roteiro e construção do vídeo tiveram auxílio de alunos do Ensino Médio e Técnico do CEFET/RJ que participavam como bolsistas do programa de Iniciação Tecnológica no Laboratório de História da Ciência.

\section{O conceito de função}

$\mathrm{O}$ atual processo de ensino-aprendizagem de função remete a associações superficiais e limitadas do conceito. Para professores e alunos, é consolidado, quase que de imediato, que o termo função é indissociável de seus tipos: função afim, função quadrática, função exponencial, função logarítmica, etc. Dessa forma, observa-se uma apropriação utilitarista e prática da Matemática para aplicação de operações e obtenção de resultados. No entanto, o conceito é preterido e o ganho intelectual potencial desse aprendizado e as possibilidades de extrapolar esses conhecimentos no cotidiano são cerceados.

Para compreender melhor o conceito devemos partir do seu desenvolvimento histórico. A história do conceito da função se divide em três etapas significativas, segundo Youschkevich (apud SOUZA \& MARIANI, 2005): a) Antiguidade: a noção de função aparecia como uma dependência de valores de forma bem intuitiva; b) Idade Média: a noção de função está ligada às representações geométricas e mecânicas; e c) Idade Moderna: a noção de função passa a ser representada por expressões analíticas.

O conceito de função passou por diversas modificações durante a história da Humanidade. Além disso, foi de extrema importância para o desenvolvimento de outras áreas da Matemática, como o cálculo e a análise. Caraça define função como:

Sejam x e y duas variáveis representativas de conjuntos de números; diz-se que y é uma função de $\mathrm{x}$ e escreve-se $\mathrm{y}=\mathrm{f}(\mathrm{x})$, se entre as duas variáveis existe uma correspondência unívoca no sentido $\mathrm{x} \rightarrow \mathrm{y}$. A $\mathrm{x}$ chama-se variável independente, a y variável dependente. (CARAÇA, 1975, p.129)

Para chegar à definição do conceito que se usa atualmente, foi necessário o desenvolvimento de outros conceitos, tais como o de variável dependente, variável independente, continuidade, domínio, contradomínio, funções analíticas, etc.

Vazquez, Rey e Boubée (2008) apresentam um pequeno resumo sobre as definições do conceito de função ao longo dos séculos: 


\begin{tabular}{|c|c|}
\hline Época & Definição \\
\hline \multirow{4}{*}{ Século XVII } & Qualquer relação entre variáveis \\
\hline & $\begin{array}{l}\text { Uma quantidade obtida de outras quantidades mediante operações algébricas ou } \\
\text { qualquer outra operação imaginável. }\end{array}$ \\
\hline & Qualquer quantidade que varia de um ponto a outro em uma curva. \\
\hline & $\begin{array}{l}\text { Quantidades formadas usando expressões algébricas e transcendentais de } \\
\text { variáveis e constantes. }\end{array}$ \\
\hline \multirow{3}{*}{ Século XVIII } & Quantidades que dependem de uma variável. \\
\hline & $\begin{array}{llcccc}\begin{array}{l}\text { Função de algumas variáveis, como quantidade, } \\
\text { composta, de alguma forma, de variáveis e constantes. }\end{array} & \text { que } & \text { é } \\
\end{array}$ \\
\hline & Qualquer expressão útil para calcular. \\
\hline \multirow{3}{*}{ Século XIX } & Correspondência entre variáveis. \\
\hline & Correspondência entre um conjunto $\mathrm{A}$ e os números reais. \\
\hline & Correspondência entre os conjuntos. \\
\hline
\end{tabular}

Quadro 1- Definições de funções ao longo dos séculos Fonte: (VAZQUEZ, REY \& BOUBÉE, 2008)

O quadro anterior apresenta uma síntese das definições que o conceito de função recebeu ao longo dos séculos, verificando-se que sofreu transformações devido às necessidades de cada época. O desenvolvimento dessas concepções foi extremamente importante para a Matemática. No entanto, vale ressaltar que o conceito de função só foi inserido como conteúdo escolar depois do século XIX (BRAGA, 2006), e essa história também tem relevância e se trata de parte do processo de constituição do currículo escolar de Matemática.

No início do século XX, havia um movimento mundial de renovação nas escolas secundárias do ensino da Matemática, que tinha bases na Alemanha, Inglaterra, França e Estados Unidos, conseguindo, ao longo do tempo, misturar o trabalho de professores, psicólogos e grandes matemáticos da época, como o matemático Christian Felix Klein (1849-1925) que teve papel importante no movimento internacional cujo objetivo era o de fazer uma reforma do ensino secundário. Klein participou de um movimento similar na Alemanha (BRAGA, 2006, p.31). A diversidade de formação era evidenciada naquela época, nos estudantes que ingressavam nas Escolas Técnicas Superiores. Muitos alunos ingressavam com muitas carências de conteúdos. O que fazia com que houvesse a necessidade de uma formação mais uniforme.

Braga (2006) relata que Klein passou a se dedicar também à formação dos professores do secundário, com objetivo de reformar o ensino da Matemática Universitária e percebeu que deveria considerar o Ensino Básico como um alicerce para a Educação Superior. O seu intuito 
inicial era de inserir o Cálculo em tal segmento escolar, no entanto, segundo o autor, houve uma restrição na inserção de tal conteúdo na Educação Básica Uma forma de inseri-lo como uma via entre o secundário e o nível superior da Matemática seria "centrar o ensino da matemática escolar no conceito de função" (p.52).

O mesmo autor salienta sobre a ideia de função na disciplina de Cálculo Diferencial e Integral:

\begin{abstract}
Aliás, cabe observar que a função revelava-se imprescindível pra a abordagem por ele proposta para a disciplinarização do Cálculo, fato este denunciado pela própria nomenclatura de seus elementos constituintes: limite de uma função, derivada de uma função num ponto, função derivada, função primitiva, integral de uma função, etc. Dessa forma, o sucesso no ensino de Cálculo estaria intimamente ligado a um bom domínio de função por parte do aluno. E mais o entrelaçamento desses dois assuntos poderia vingar se o educando soubesse transitar com relativo desembaraço pelas várias representações de função. (BRAGA, 2006, p.52).
\end{abstract}

De acordo com Klein, para o ensino de Cálculo era necessário um bom domínio de função, além disso, após a proibição do ensino do Cálculo, a função seria o caminho mais fácil de inserir um conteúdo para facilitar esse ensino na Educação Superior.

Braga (2006) também aborda em seu trabalho, como o conceito de função foi inserido no currículo de Matemática do Brasil:

O processo de inserção do tema função entre os conteúdos da nossa matemática do secundário está diretamente vinculado à criação, concretizada no ano letivo de 1929, de uma nova disciplina escolar do ensino brasileiro, denominada matemática, resultante da unificação de três outras, até então, independentes: a aritmética, a álgebra e a geometria. Essa fusão é feita a partir de uma referência internacional [...] cujo epicentro se encontra nas ideias do renomado matemático prussiano Felix Klein, que propunha uma renovação nesse nível de ensino.

Essa transformação estrutural da nossa matemática escolar é, em 1931, referendado por uma reforma educacional mais ampla, conhecida como Reforma Francisco Campos. (BRAGA, 2006, p. 25).

Percebe-se, assim, a importância histórica para inserção desse conteúdo ao currículo de Matemática, uma vez que ainda é um assunto moderno.

\title{
3 História da Ciência e da Matemática no Ensino
}

No artigo intitulado História, Filosofia e Ensino de Ciências: A tendência atual de reaproximação, Michael Matthews (1995) aborda várias questões sobre a utilização da História da Ciência no ensino, apresentando argumentos a favor e contra a história aplicada ao ensino. 
O autor constata a crise em que os sistemas educacionais se encontravam na época da escrita do seu trabalho, pela evasão de estudantes e professores, os grandes índices de analfabetismo em Ciências e a baixa qualidade dos cursos de Ciências e Matemática. Tal cenário apresentado ainda é percebido nos dias atuais. Segundo o autor, a História, a Filosofia e a Sociologia não têm todas as respostas, no entanto contribuem para humanizar as ciências e fazer uma aproximação aos interesses discentes, além de possibilitar que as aulas se tornem mais desafiadoras e contribuir para dar significado aos conteúdos.

Matthews (1995) afirma que os defensores da utilização da História da Ciência advogam pela contextualização das Ciências, caracterizando assim que o ensino deva ser "em e sobre Ciências" (p. 166). Também reitera que essa tradição contribui para o ensino por: a) Motivar e atrair alunos; b) Humanizar a matéria; c) Promover uma melhor compreensão dos conceitos científicos; d) Haver um valor intrínseco na compreensão de certos episódios da História da Ciência; e) Demonstrar que a ciência é mutável e instável; f) Opor-se à ideologia cientificista; g) Permitir uma compreensão do método científico através da história, apresentando os padrões de mudança na metodologia.

Ao considerarmos a história como uma peça fundamental no processo de contextualização das ciências percebe-se que a História da Matemática desempenha um papel importante no processo de ensino e aprendizagem, já que pode auxiliar na construção dos significados dos conceitos matemáticos e na contextualização de como tais conceitos foram sendo construídos e reconstruídos ao longo dos anos.

Miguel e Miorim (2008) consideram que "as histórias podem e devem constituir pontos de referência para a problematização pedagógica da cultura escolar e, mais particularmente, da cultura matemática" (p. 156), e afirmam que devem ser construídas com fins explicitamente pedagógicos, além de estarem articulados com as outras variáveis que geram intervenção no processo de ensino-aprendizagem da Matemática. A simples inserção da História da Matemática dentro da sala de aula, não garante a melhoria na aprendizagem.

Sobre o uso da História da Matemática no ensino, escrita por matemáticos ou historiadores, Miguel e Miorim (2008) acreditam que não realça alguns elementos e aspectos que poderiam, além de não trazer uma real contribuição aos professores em suas aulas, já que essa história não foi feita com tal objetivo. 
Exatamente sobre a necessidade de se constituir uma História da Matemática para ser utilizada na sala de aula, Miguel e Miorim (2008) afirmam a necessidade de se constituir histórias que tenham uma preocupação educativa. Assim, se considera a História da Matemática pedagogicamente vetorizada que :

[...] não é nem uma história adocicada ou suavizada, nem uma história distorcida, nem uma adaptação ou transposição didática das "verdadeiras" histórias da Matemática para o âmbito da escola. Uma característica inicial de tal tipo de história diz respeito ao fato de pretender uma história institucional da cultura da matemática. Como a escola é uma dentre outras instituições sociais constituídas para cumprir finalidade específica dentro de um contexto social... (MIGUEL \& MIORIM, 2008, p.157).

Tal história é construída para atender as demandas institucionais nas quais estão inseridos os participantes do processo educativo. Os referidos autores afirmam que, para a constituição dessas histórias, deve-se "partir de problemas e questões que emergem das e/ou se relacionam com as práticas sociais, nas quais a cultura Matemática se acha envolvida" (2008, p.158). Sendo assim, as histórias pedagogicamente vetorizadas devem ser mais do que meramente histórias das ideias matemáticas, devem ser histórias de diferentes culturas matemáticas que se constituíram a partir de distintas práticas sociais.

\section{Tecnologia Educacional}

O uso das tecnologias no ensino é um assunto muito pertinente em nossa sociedade, pois os recursos tecnológicos estão por toda parte. Segundo Kenski (2007), a evolução tecnológica não está restrita somente aos novos usos de equipamentos, pois ela altera também o comportamento. As novas tecnologias são as mais recentes, que com o passar do tempo serão apenas tecnologias após um processo de banalização e fácil acesso. Como se podem inserir os novos recursos dentro da sala de aula? A questão não se restringe ao simples uso por parte do professor de tais recursos, mas de como e quando usar.

Kenski (2007) afirma que a incorporação das tecnologias na educação deve partir do entendimento de seu uso e compreensão no universo escolar e não simplesmente colocar os recursos em sala, sem o menor preparo. Não basta inserir as tecnologias, é preciso rever as metodologias de ensino. 
O fato de inserir novas tecnologias digitais, por si só "não oferece aos seus usuários um novo mundo sem problemas" (op.cit, p.53). Esse fato é uma consequência do pioneirismo da revolução tecnológica na sociedade.

Usar adequadamente as tecnologias na sala de aula, de forma pedagógica, e compreender melhor o mundo tecnológico em que se vive, além de fazer uso do diálogo, auxilia na sala de aula. No entanto, para Kenski (2007), mais importantes do que usar tecnologias, o que faz a diferença é a capacidade de adequar os recursos em função do processo educativo, cujo objetivo é a aprendizagem do aluno.

Moran (2007) observa, que os meios de comunicação audiovisuais (televisão, vídeo e cinema), indiretamente, possuem um papel educacional relevante, que além de passar, continuamente, informações interpretadas, mostram modelos de comportamento e dão privilégio a alguns valores em detrimento de outros.

Sobre a linguagem do audiovisual, o mesmo autor afirma que "desenvolve múltiplas atitudes perceptivas: solicita constantemente a imaginação e reinveste a afetividade com um papel de mediação primordial do mundo" (1995)

E indica ainda as seguintes propostas para utilização em sala de aula: a) sensibilização; b)

ilustração; c) simulação; d) conteúdo de ensino; e) produção; f) avaliação; g) espelho e h) integração suporte.

Sant'Anna e Sant'Anna (2004) afirmam que os recursos audiovisuais propiciam: a) Memorização eficiente; b) Interpretação com maior clareza; c) Facilitação da compreensão; d) Aprendizagem rápida, eficaz e duradoura; e e) Aquisição de novos conhecimentos. Sendo assim, tais recursos se mostram com um potencial que pode auxiliar no processo de aquisição do conhecimento, facilitando a aprendizagem significativa.

\section{Metodologia}

Com o intuito de utilizar a História da Matemática como estratégia para ensinar funções, foram construídos alguns materiais didáticos, entre eles um vídeo em formato de documentário sobre a história do conceito de função, um caderno de atividades e uma avaliação diagnóstica.

No primeiro momento, realizou-se uma pesquisa bibliográfica cujo objetivo era fazer o levantamento dos aspectos importantes para o processo de ensino-aprendizagem da temática de 
funções, cujo caráter pedagógico deve ser valorizado na construção desse conceito. Os aspectos relevantes encontrados são: a) o conceito de função deve valorizar a dependência entre variáveis; b) o conceito de função deve ser apresentado por suas várias representações; c) o conceito de função deve ser associado com a resolução de problemas contextualizados; d) o conceito de função deve ser utilizado como modelo matemático para as outras ciências; e e) o conceito de função deve ser compreendido através do problema da variabilidade.

Percebeu-se a necessidade de coletar alguns dados para analisar a aplicação do vídeo e para identificar eventuais problemas com a sua exibição, visando obter uma aprendizagem significativa. Sendo assim, elaboraram-se instrumentos que: a) mensurassem o grau de conhecimento matemático específico antes da utilização do vídeo; b) promovessem a fixação dos conteúdos abordados no vídeo; e c) mensurassem o grau de conhecimento após a intervenção proposta nesse trabalho. Com base no exposto, foram preparados: a) um teste de avaliação inicial, chamado de Pré-Teste; b) exercícios de fixação, que compuseram o Caderno de Atividades para aplicação após o vídeo; e c) um teste após a realização do Caderno de Atividades, chamado de Pós-Teste.

O processo de elaboração do vídeo demandou grande empenho e tempo dos envolvidos, visto que as ações realizadas visaram a construção de um produto educacional. Desta forma, as etapas foram categorizadas de modo a facilitar a compreensão, em três momentos distintos, a saber: a) aprofundamento teórico do tema em questão; b) elaboração do roteiro; e c) produção e edição do vídeo.

Na primeira etapa, priorizou-se uma bibliografia que versasse sobre a história do conceito de função, aspectos importantes sobre o seu ensino e os aspectos históricos relevantes a seu ensino e sua aprendizagem. As pesquisas foram realizadas em livros de História da Matemática, artigos, dissertações e teses sob o descritor história do conceito de função. Durante essa etapa, percebeu-se a necessidade de pesquisas voltadas para a História da Ciência, tendo em vista compreender melhor a motivação para o estudo de funções ao longo dos séculos, mas também pela carência dos materiais sobre história da Matemática, além de alguns erros históricos encontrados, como por exemplo, chamar a Idade Média de Idade das Trevas.

$\mathrm{Na}$ segunda etapa, realizou-se a construção do roteiro baseado nas informações encontradas na pesquisa bibliográfica. Nesse ponto, tentou-se assumir como eixo para construção a História da Matemática pedagogicamente vetorizada (MIGUEL e MIORIM, 2008). Na 
elaboração do roteiro consideraram-se os aspectos importantes sobre o ensino de função, os aspectos históricos relevantes, a necessidade de uma linguagem apropriada ao Ensino Básico e a contextualização histórica no processo de construção do conceito.

A produção do vídeo contou com a participação de três alunos do Ensino Médio e Técnico do CEFET/RJ, que eram bolsistas de Iniciação Tecnológica do Laboratório de História da Ciência daquela instituição. Eles contribuíram com a elaboração do roteiro, pesquisa iconográfica, produção e edição das imagens, narração e apresentação do vídeo. A sua participação foi registrada nos relatórios que apresentaram ao final desse projeto de iniciação científica. Os bolsistas participantes já tinham experiência na produção de vídeos educativos e ainda cursavam o Ensino Médio, o que foi importante para adequar a linguagem voltada para os estudantes telespectadores do vídeo.

A partir do levantamento bibliográfico que determinou quais aspectos eram relevantes para a aprendizagem de função, notou-se a necessidade da construção de um material que pudesse contribuir para o entendimento matemático sobre o conceito de função. Dessa forma, foi construído um caderno com atividades selecionadas que contemplassem os objetivos descritos nos documentos oficiais. O Caderno possui tarefas que auxiliam na compreensão das várias formas de representação das funções, seja por tabelas, gráfico, fórmulas, etc. As atividades foram organizadas de acordo com a sequência do desenvolvimento histórico do conceito apresentado no vídeo, permitindo posteriormente a análise da recepção do vídeo pelos alunos. Esse Caderno contempla, também, questões que abordam a variabilidade de funções. A partir do caderno percebeu-se a necessidade de fazer com que o vídeo fosse divido em quatro pequenos vídeos ${ }^{1}$ para facilitar o entendimento.

Com a proposta de promover uma avaliação inclusiva e que permitisse analisar a contribuição da intervenção proposta nesse processo de ensino-aprendizagem, optou-se por realizar uma averiguação prévia dos conceitos, chamada de Pré-Teste e outra após este processo, com o mesmo instrumento avaliativo. Esse foi composto de 10 questões fechadas, com 4 ou 5 alternativas, porém uma única resposta correta.

\footnotetext{
${ }^{1}$ Os vídeos produzidos para a pesquisa estão disponibilizados nos endereços:

Vídeo 1- http://www.youtube.com/watch?v=pYQzdY40yr8

Vídeo 2- http://www.youtube.com/watch?v=35OIMMUFAuk

Vídeo 3- http://www.youtube.com/watch?v=OK5FrN4E7b4

Vídeo 4- http://www.youtube.com/watch?v=HZLREejrDP0
} 
A intervenção em sala de aula ocorreu com os alunos do $1^{\circ}$ ano do Ensino Médio da Colégio Estadual Irmã Cecília Jardim, localizada na cidade de Petrópolis, situada no Estado do Rio de Janeiro. A escola possui aproximadamente 300 alunos no $1^{\circ}$ ano e 24 alunos participaram.

As atividades foram ordenadas da seguinte forma: 1) aplicação do Pré-Teste; 2) exibição do Vídeo; 3 ) resolução do Caderno de Atividades; e 4) aplicação do Pós-Teste. No entanto, como o Vídeo foi divido em quatro partes, ao final de cada seção, foram resolvidos os exercícios referentes à exibição.

O tempo reservado para essa intervenção correspondeu a 4 aulas com duração de 50 minutos cada, assim distribuído: a) Pré-Teste: até 50 minutos; b) Exibição do vídeo e resolução de exercícios: até 200 minutos; e c) Pós-Teste: até 50 minutos.

\section{Discussão e Resultados}

A pesquisa em questão teve por objetivo possibilitar um processo de ensino-aprendizagem significativo do conceito de função por meio da História da Matemática. A pesquisa bibliográfica demonstrou a escassez de abordagem sobre esse tema e a dificuldade de encontrar literatura com linguagem apropriada ao Ensino Básico. Os materiais de História da Matemática sozinhos não foram suficientes para o entendimento das transformações sofridas pelo conceito. Houve a necessidade de utilização de materiais ligados a História da Ciência.

Com o intuito de despertar o interesse dos alunos para a Matemática, foi necessário tornar o processo de aquisição do conhecimento em uma disciplina palpável, relacionando com a sua realidade. A utilização da História da Matemática permite a esses alunos entender de que forma a disciplina se desenvolveu e auxilia na compreensão do mundo, e porque se estuda a Matemática, e como ela se insere na história da humanidade e compreender que a disciplina não é um saber pronto e estático, mas que tem sido sistematizado ao longo dos séculos para a resolução das demandas humanas.

A história do conceito de função, em vídeo, permite aos alunos perceber como o conceito mudou ao longo dos séculos e que sua transformação ocorreu à medida que a sociedade se desenvolveu. O processo de construção com o auxílio de bolsistas de iniciação tecnológica, sob supervisão, evidenciou o potencial da produção de vídeos históricos com o apoio de estudantes do Ensino Médio. Por meio dos relatórios produzidos por eles, verificou-se que tal proposta permitiu: a) adequação da linguagem do vídeo; b) processo de pesquisa e leitura de textos 
históricos, contribuindo para entendimento e busca na compreensão do conceito; c) desenvolvimento de habilidades de escrita e síntese para o roteiro; d) seleção de imagens baseada no roteiro e nos textos lidos; e) produção e edição do vídeo utilizando softwares específicos. Essa participação colocou-os como agentes ativos no processo de aprendizagem.

Após o processo de produção dos recursos didáticos, optou-se por aplicá-los em uma turma de $1^{\circ}$ ano do Ensino Médio, para analisar o potencial do vídeo e dos outros recursos e para levantar dados sobre o que poderia ser melhorado para facilitar a aprendizagem do conceito de função por meio da história. O processo de aplicação foi dividido em seis etapas inicialmente divididas em 50 minutos com intervalos de 10 a 20 minutos. A primeira e a sexta etapa eram para realização das avaliações (Pré-Teste e Pós-Teste). Da segunda a quinta etapa era da exibição dos vídeos e da realização de atividades pertinentes ao que tinha sido exibido no vídeo e que coletavam informações sobre a recepção do vídeo e aprofundamento da temática.

As etapas são descritas no quadro a seguir com algumas observações a respeito da aplicação de cada uma delas:

\begin{tabular}{|c|l|l|}
\hline ETAPA & \multicolumn{1}{|c|}{ DESCRIÇÃO } & \multicolumn{1}{c|}{ OBSERVAÇÕES } \\
\hline $1^{\mathrm{a}}$ & Aplicação do Pré-teste & Etapa ocorreu sem nenhum problema. \\
\hline $2^{\mathrm{a}}$ & $\begin{array}{l}\text { Exibição da Primeira parte do } \\
\text { Vídeo e aplicação de } \\
\text { atividades relacionadas }\end{array}$ & $\begin{array}{l}\text { A exibição do vídeo ocorreu normalmente, alunos atentos as } \\
\text { informações. A partir de atividades específicas percebe-se que } \\
\text { houve a compreensão do que foi abordado no vídeo. Alunos } \\
\text { apresentam algumas dificuldades na leitura de questões e } \\
\text { resolução de atividades que }\end{array}$ \\
\hline $3^{\text {a }}$ & $\begin{array}{l}\text { Exibição da Segunda parte do } \\
\text { Vídeo e aplicação de } \\
\text { atividades relacionadas }\end{array}$ & $\begin{array}{l}\text { Exibição ocorre sem problemas. Alunos apresentam dificuldades } \\
\text { em entender certas palavras no caderno de atividades }\end{array}$ \\
\hline $4^{\text {a }}$ & $\begin{array}{l}\text { Exibição da Terceira parte do } \\
\text { Vídeo e aplicação de } \\
\text { atividades relacionadas }\end{array}$ & $\begin{array}{l}\text { Exibição sem problemas . Alunos apresentam sinal de cansaço na } \\
\text { realização das atividades. }\end{array}$ \\
\hline $5^{\text {a }}$ & $\begin{array}{l}\text { Exibição da Quarta parte do } \\
\text { Vídeo e aplicação de } \\
\text { atividades relacionadas }\end{array}$ & $\begin{array}{l}\text { Exibição sem problemas com alunos atentos. Atividades são } \\
\text { deixadas em branco por falta de entendimento e cansaço por parte } \\
\text { dos discentes. }\end{array}$ \\
\hline $6^{\text {a }}$ & $\begin{array}{l}\text { Aplicação do Pós-Teste } \\
\text { Ocorre sem problemas. }\end{array}$ \\
\hline
\end{tabular}

Quadro 2- Etapas de aplicação dos produtos educacionais

Fonte: (Maciel, 2011)

A partir da observação em sala e da análise de algumas questões específicas do caderno de atividades, que foram utilizadas para a recepção do vídeo e se houve entendimento das partes pelos alunos, pode-se afirmar que a utilização do vídeo foi capaz de promover nos alunos o interesse e motivação para aprender Matemática, além de compreensão do conceito de função. Observou-se que os alunos perguntaram muito sobre o entendimento de algumas atividades, 
demonstrando a inabilidade com a interpretação e compreensão do enunciado, além de desconhecimento de termos como inflação, definição de grandezas, entre outros.

Todos os participantes concluíram as etapas de intervenção. Com base nos dados das questões referentes a aprofundamento da temática função, em cada etapa do caderno de atividades, se traçam os seguintes comentários sobre os alunos: a) Apresentaram dificuldades com conceitos e operações de Matemática do Ensino Fundamental como: proporção e operações com inteiros; não conseguiram trabalhar com expressões algébricas; tiveram grande dificuldade em generalizar os casos, ou seja, escrever as funções como fórmulas; b) Apresentaram dificuldades em marcar pontos no plano cartesiano; c) Não conseguiram compreender e interpretar as solicitações; d) Demonstraram inabilidade na utilização da língua materna, tanto na escrita quanto na leitura; e) Não possuíam o hábito de resolver exercícios em formato de problemas, estão acostumados com exercícios diretos, resolva, efetue.

A seguir apresentam-se alguns exemplos de questões encontradas no caderno de atividades:

\begin{tabular}{|c|c|}
\hline $\begin{array}{l}\text { Número da } \\
\text { Atividade }\end{array}$ & Atividade apresentada de forma Parcial \\
\hline 1 & $\begin{array}{l}\text { a) Desenhe a próxima figura e complete a quantidade de lápis. } \\
\text { Figura } 1 \\
\text { b) Você notou uma regra de formação? Para obter mais um } \\
\text { triângulo basta acrescentar sempre mais _ápenis. } \\
\text { c) Cada novo triângulo é formado apenas acrescentando mais } \\
\text { lápis, porém o primeiro triângulo precisou de_ lápis, a } \\
\text { mais que qualquer outro. } \\
\text { d) Termine de preencher os valores correspondentes na tabela } \\
\text { abaixo, onde T é a quantidade de triângulos formados com L } \\
\text { lápis. }\end{array}$ \\
\hline 15 & $\begin{array}{l}\text { Uma garrafa de } 500 \mathrm{ml} \text { de suco concentrado deve ser dissolvida em } 1 \\
\text { litro de água para obtermos um suco reconstituído. } \\
\text { a) Se utilizarmos todo o suco concentrado de uma garrafa, quantos litros } \\
\text { teremos de suco pronto para beber: } \\
\text { b) Queremos servir suco no almoço de domingo para toda a família } \\
\text { presente. Quantos litros de suco pronto vamos preparar usando } 2 \text { garrafas } \\
\text { de suco concentrado? } \\
\text { c) Complete a tabela, onde c é o total de garrafas de suco concentrado e } \\
\text { Lé o total de litros de suco pronto: }\end{array}$ \\
\hline
\end{tabular}




\begin{tabular}{|c|c|c|c|c|c|c|c|c|c|c|}
\hline & C & 1 & 2 & 3 & & 4 & 5 & 6 & & \\
\hline & L & & & & & & & & & \\
\hline & $\begin{array}{l}\text { d) Se você } \\
\mathrm{L}(\mathrm{c}) \text {, com } \\
\text { aparecendo }\end{array}$ & $\begin{array}{l}\text { narce } \\
\text { alore } \\
\text { la fig }\end{array}$ & $\begin{array}{l}\text { lo } \mathrm{p} \\
\text { ada } \\
?\end{array}$ & $\begin{array}{l}\text { o ca } \\
\mathrm{z} \mathrm{ma}\end{array}$ & $\begin{array}{l}\text { tesian } \\
\text { s pró }\end{array}$ & $\begin{array}{l}\text { outrc } \\
\text { imos }\end{array}$ & $\begin{array}{l}\text { pon } \\
\text { ns de }\end{array}$ & $\begin{array}{l}\text { s dad } \\
\text { outr }\end{array}$ & $\begin{array}{l}\text { s na } \\
\text {, o }\end{array}$ & $\begin{array}{l}\text { unção } \\
\text { le vai }\end{array}$ \\
\hline & $\begin{array}{l}\text { Um móvel } \\
\text { informa a pc }\end{array}$ & $\begin{array}{l}\text { se lo } \\
\text { sição }\end{array}$ & $\begin{array}{l}\text { mov } \\
\text { mó }\end{array}$ & em & $\begin{array}{l}\text { iceler } \\
\mathrm{m} \text { dac }\end{array}$ & $\begin{array}{l}\text { ção c } \\
\text { o insta }\end{array}$ & $\begin{array}{l}\text { astan } \\
\text { te. }\end{array}$ & $\mathrm{A}$ & bela & baixo \\
\hline & Tempo (s) & 0 & 1 & 2 & 3 & 4 & 5 & 6 & 7 & 8 \\
\hline & Posição (m) & 0 & 0,1 & 0,4 & 0,9 & 1,6 & 2,5 & 3,6 & 4,9 & 6,4 \\
\hline 17 & $\begin{array}{l}\text { a) Qual foi a } \\
\text { b) Qual foi } \\
\text { c) A velocic } \\
\text { nos } 4 \text { último } \\
\text { d) Qual foi } \\
\text { e) Qual foi a } \\
\text { f) Qual foi a }\end{array}$ & $\begin{array}{l}\text { velo } \\
\text { velo } \\
\text { ade } r \\
\text { seg } \\
\text { velo } \\
\text { velo } \\
\text { velo }\end{array}$ & $\begin{array}{l}\text { ade } 1 \\
\text { ade } \\
\text { lia d } \\
\text { os d } \\
\text { ade } \\
\text { ade } 1 \\
\text { de r }\end{array}$ & $\begin{array}{l}\text { dia c } \\
\text { dia c } \\
\text { nóve } \\
\text { eu n } \\
\text { dia c } \\
\text { dia o } \\
\text { dia d }\end{array}$ & $\begin{array}{l}\text { móv } \\
\text { móv } \\
\text { foi } n \\
\text { vime } \\
\text { móv } \\
\text { móv } \\
\text { móv }\end{array}$ & $\begin{array}{l}1 \text { nos c } \\
\text { l nos } 8 \\
\text { aior no } \\
\text { to? } \\
\text { l entre } \\
1 \text { entre } \\
\text { l entre }\end{array}$ & $\begin{array}{l}\text { is pr } \\
\text { prim } \\
4 \mathrm{pr} \\
\text { os ins } \\
\text { os ins } \\
\text { s ins }\end{array}$ & $\begin{array}{l}\text { neiros } \\
\text { os se } \\
\text { neiros } \\
\text { ntes } \\
\text { ntes } \\
\text { ntes t }\end{array}$ & $\begin{array}{l}\text { egur } \\
\text { ando } \\
\text { egu } \\
1 \mathrm{~s} \mathrm{e} \\
2 \mathrm{~s} \mathrm{e} \\
3 \mathrm{~s} \mathrm{e}\end{array}$ & $\begin{array}{l}\text { los? } \\
\text { los ou } \\
=2 \mathrm{~s} ? \\
=3 \mathrm{~s} ? \\
=4 \mathrm{~s} ?\end{array}$ \\
\hline
\end{tabular}

Quadro 3- Exemplos de questões do Caderno de Atividades Fonte: (Maciel, 2011)

O gráfico a seguir foi estruturado a partir do caderno de atividade que foi composto de 21 atividades para ampliar o conceito de função e analisar a recepção do vídeo, marcadas no eixo $\mathrm{X}$ e o quantitativo de alunos no eixo Y. Foram categorizadas quatro possíveis alternativas de enquadramento dos alunos: $1^{\circ}$ ) Acertos para quem respondeu corretamente a questão; $2^{\circ}$ ) Acertos parciais para quem teve acerto igual ou maior a cinquenta por cento da questão; $3^{\circ}$ ) Para quem errou a questão ou acertou menos de cinquenta por cento; e $4^{\circ}$ ) Em branco para quem não respondeu.

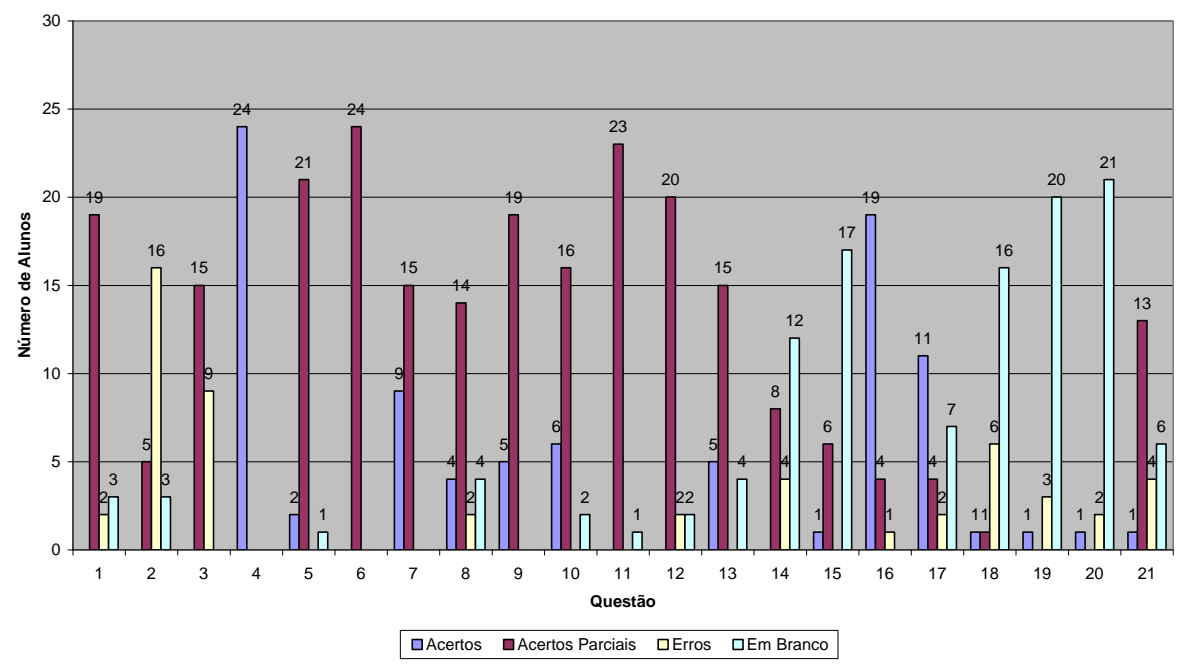

Gráfico I - Acertos e erros dos alunos no caderno de atividades 
Fonte: (Maciel, 2011, p. 60)

Observa-se que as questões 1, 6, 11 e 16 eram para verificar o entendimento da recepção do vídeo pelos alunos em cada uma das etapas de exibição apresentadas.

Os objetivos propostos eram desenvolver um aprofundamento sobre funções, no entanto, percebeu-se que a carência de conteúdos prévios, do Ensino Fundamental, comprometeu a compreensão dos enunciados das atividades, que interferiram na resolução dos mesmos.

Com a análise das atividades discursivas de ampliação do conceito, foi possível elencar possíveis nós críticos no processo de ensino-aprendizagem em Matemática, que são experimentados pelos alunos de Ensino Médio dessa escola. O caderno significou uma fonte de dados enriquecedora, posto que demonstrou fatores potencialmente responsáveis para uma apropriação inadequada e com baixo aproveitamento do conceito de função que não apenas relacionada ao método adotado em si.

$\mathrm{Na}$ análise comparativa entre os resultados obtidos na aplicação das avaliações, constatouse não haver diferença expressiva no desempenho individual e coletivo. A intervenção empregada verificou que o vídeo foi capaz de promover um entendimento da constituição da história da função que foi comprovado nas questões definidas para a recepção do vídeo pelos alunos, no entanto, o caderno de Caderno de Atividades com as atividades para ampliação do conceito trabalhado no vídeo, demonstrou as fraquezas de conteúdos nos alunos. Como hipóteses para o baixo desempenho discente têm-se: a) o processo ter ocorrido em um período de tempo muito curto; b) necessidade de maior intervalo de tempo para que os alunos possam maturar as ideias trabalhadas com os recursos; c) a baixa proficiência em conteúdos prévios que servem de prérequisitos matemáticos, percebidos na correção do caderno de atividades e da interpretação dos tópicos; d) a redução do tempo, por parte dos alunos, para a resolução do Pós-Teste em relação ao Pré-teste; e e) o fato das questões do pré e pós teste serem as mesmas, o que pode ter provocado resistência para uma nova resolução.

Apresentam-se os dados tabulados que serviram de base para análise do desempenho discente, bem como para compreensão do desfecho dos testes, a partir da análise das questões discursivas.

O desempenho percentual dos alunos nos testes (pré e pós) está representado na tabela a seguir. Tem-se um panorama dos resultados, onde as questões foram marcadas no eixo X e o percentual de acertos no eixo Y. As questões com maior número de acertos foram as de número 
7, no pós-teste, e 10, no pré-teste. A questão com menor número de acertos foi a de número 3, no pré-teste.

Tabela 1 - Percentual de acertos das avalições

Fonte: (Maciel, 2011)

\begin{tabular}{c|r|r}
\hline & \multicolumn{2}{|c}{ Acertos teste $(\%)$} \\
Questão & \multicolumn{1}{c}{ Pré } & \multicolumn{1}{c}{ Pós } \\
\hline 1 & 20,83 & 8,33 \\
\hline 2 & 16,66 & 16,66 \\
\hline 3 & 25 & 12,5 \\
\hline 4 & 12,5 & 16,66 \\
\hline 5 & 4,16 & 16,66 \\
\hline 6 & 29,16 & 29,16 \\
\hline 7 & 29,16 & 41,66 \\
\hline 8 & 16,66 & 20,83 \\
\hline 9 & 33,33 & 20,83 \\
\hline 10 & 41,66 & 37,5 \\
\hline
\end{tabular}

Neste processo de intervenção, os alunos foram submetidos a duas avaliações, com o objetivo de compará-las. No entanto, a compreensão e entendimento do raciocínio matemático não ficariam explícitos, porque foram compostos de questões objetivas.

\section{Considerações Finais}

Para a elaboração dessa história foi necessário recorrer a três histórias e correlacioná-las a fim de promover uma construção coerente e sólida sobre o desenvolvimento do conceito, a saber: Histórias da Matemática, da Ciência e da Humanidade. Logo, confirmou-se o caráter dinâmico, não só do conceito de função, mas como também do da Matemática.

No processo de elaboração do vídeo, os alunos envolvidos puderam aprender e apreender, de maneira informal, o tema, sinalizando um potencial pedagógico de grande valia, digno de ser relatado. Assim, vislumbra-se mais uma alternativa de trabalho com os discentes que viabilize um processo de ensino-aprendizagem inclusivo e prazeroso, uma vez que se percebeu um grande potencial desse recurso na inserção dos alunos tanto na produção, quanto para serem telespectadores críticos. 
Assim, a utilização do vídeo como um recurso didático evidenciou que os alunos são atraídos por esse tipo de mídia, tornando-os mais receptivos aos novos conteúdos, pois sendo submetidos à exibição do vídeo, interessaram-se pelo conteúdo e pelo fato de ter sido construído com auxílio de outros alunos do Ensino Médio. A aplicação do vídeo demonstrou que os alunos conseguiram compreender o conceito apresentado no vídeo, no entanto, a partir das atividades do material elaborado, que visavam promover um aprofundamento do conteúdo, não conseguiram atingir sua plenitude. Observou-se que o processo de ensino-aprendizagem sobre o conceito de função necessita de conhecimentos matemáticos prévios - os quais os alunos demonstraram, por meio de caderno de atividades, não possuírem adequadamente - o que comprometeu a aquisição do novo conteúdo. Dessa forma, o material construído evidenciou em sua primeira aplicação alguns pontos que precisam ser melhorados para que se alcance sucesso com a utilização do vídeo histórico e dos materiais para desenvolver o conteúdo matemático.

Os resultados da pesquisa demonstram que o rendimento no desempenho dos alunos auferidos pelos instrumentos utilizados na intervenção proposta não é necessariamente devido ao Conceito de Função, os resultados expressam a falta de conhecimentos básicos para o entendimento de um novo conceito. Pela análise dos cadernos de atividades, foi possível averiguar as possíveis causas, a inabilidade e inaptidão dos alunos com conteúdos nãomatemáticos e matemáticos. Entre alguns itens para a não realização das atividades mencionadas, foi explícita a dificuldade dos alunos na compreensão de alguns dos enunciados dos exercícios, na utilização incorreta da linguagem escrita e no desconhecimento do significado de vocábulos que permeiam os conhecimentos gerais, inerentes aos alunos. Percebeu-se também a dificuldade em resgatar conhecimentos matemáticos prévios e necessários para a resolução dos exercícios, dificuldade em realizar generalizações e abstrações. Assim, compreendem-se os resultados expressos nos exames de larga escala e nesse trabalho.

Ficou evidente que a utilização de novas metodologias, de tecnologias de informação e comunicação, estratégias de conteúdos mais atraentes e o processo de construção de vídeos históricos, onde os alunos se colocam como ativos no processo de aprendizagem, representou um ganho significativo no que tange a desenvolver competências e habilidades como trabalho colaborativo, iniciação à pesquisa histórica, síntese e produção de recursos audiovisuais. A aplicação da pesquisa constatou os pontos fracos dos alunos e o ponto de partida para melhorar os recursos e até mesmo o ensino de funções, para que se demonstre um processo mais eficaz. É 
necessário que, além de uma escolha planejada, se realize uma contextualização dos conteúdos, adequação aos alunos que receberam essa proposta e avaliação dos conceitos prévios para a compreensão dos objetivos em voga para que componham o novo material.

Esse produto, por meio de sua aplicação piloto, demonstrou grande potencial de auxílio ao docente na perspectiva de categorizar os déficits e demonstrar as defasagens de conteúdos dos alunos em uma prática pedagógica que despertou o interesse deles para a participação em sala, demonstrou potencial transformador da dinâmica do processo de ensino-aprendizagem, redefiniu os papéis na sala de aula - onde o professor passou a ser o mediador e os alunos tendem a superar a postura passiva frente ao conhecimento.

A avaliação dos resultados tem função propositiva, visto que não se findará com uma mera nota. A proposta é de realizar as reformulações necessárias para garantir uma adequação dos instrumentos utilizados para a construção de um saber que não se limite ao conceito de função ou aos conceitos necessários para a compreensão do conceito, mas um saber que eduque para compreensão do mundo e para o entendimento de como as disciplinas estão diretamente ligadas aos acontecimentos cotidianos.

\section{Referências}

BRAGA, C. Função a alma do ensino da matemática. São Paulo: Annablume; Fapesp, 2006. 172 p.

BRASIL. Ministério da Educação. Plano de Desenvolvimento da Educação: SAEB: ensino Médio: Matriz de Referência, tópicos e descritores. Brasília: MEC, SEB; Inep, 2008. 127 p.

BRASIL. Ministério da Educação. Secretaria de Educação Fundamental. Parâmetros Curriculares Nacionais-2 ed - Rio de Janeiro: DP\&A, 2000a. 142 p.

BRASIL. Secretaria de Educação Média e Tecnológica. Parâmetros curriculares para o ensino Médio (PCNEM). ParteIII - Ciências da Natureza, Matemática e suas tecnologias. Brasília: MEC/SEMT, 2000b.

BRASIL. Secretaria de Educação Básica. Orientações Curriculares para o Ensino Médio. Ciências da Natureza, Matemática e suas tecnologias. Brasília: Ministério da Educação, Secretaria da Educação Básica, 2006.

BRASIL. Secretaria de Educação Média e Tecnológica. PCN+ Ensino Médio: Orientações educacionais complementares aos Parâmetros curriculares. Ciências da Natureza, Matemática e suas tecnologias. Brasília: MEC/SEMT, 2002. 
CARAÇA, B.J. Conceitos Fundamentais da Matemática. Lisboa. Portugal: Livraria Sá da Costa Editora, 1975.

KENSKI, V. M. Educação e Tecnologias: O novo ritmo da informação. Campinas, SP: Papiros, 2007. 141p.

Maciel, P. R. C. A construção do conceito de função através da História da Matemática. 2011. 95f. Dissertação (Mestrado em Ensino de Ciências e Matemática) - Programa de Pós-Graduação em Ensino de Ciências e Matemática,Centro Federal de Educação Tecnológica Celso Suckow da Fonseca, Rio de Janeiro, 2011.

MARQUES, E. O. Resultados de testes de larga escala: um ponto de partida para ações de formação continuada de professores em matemática. 2008. 129 f. Dissertação (Mestrado em Ensino de Matemática) Programa de Pós-Graduação em Ensino de Matemática UFRJ. Rio de Janeiro. Disponível em: <http://www.pg.im.ufrj.br/pemat/03\%20Elizabeth\%20Ogliari.pdf > Acesso em 29 set. 2009

MATTHEWS, M. R. História, Filosofia e Ensino de Ciências: A Tendência atual de Reaproximação. Caderno Catarinense do Ensino de Física. Florianópolis. v. 12, n. 3, p.164-214, dez. 1995.

MIGUEL, A.; MIORIM, M. A. História na Educação Matemática: Propostas e desafios. Belo Horizonte: Autêntica, 2008. 200 p.

MORAN, J. M. Desafios na Comunicação Pessoal. $3^{\text {a }}$ Edição. São Paulo: Paulinas, 2007.

MORAN, J. M. O vídeo na sala de Aula. Comunicação \& Educação. São Paulo, n. 2, p. 27-35, jan/abr. 1995. Disponível em: < http://www.revistas.usp.br/comueduc/issue/view/2965>. Acesso em: 10 de set. 2013.

RIO DE JANEIRO. Secretaria de Estado da Educação. Revista do Professor de Avaliação da Educação /Universidade Federal de Juiz de Fora, Faculdade de Educação, Caed. Juiz de Fora, v.1, s/n. jan/dez. 2008.

RIO DE JANEIRO. Secretaria de Estado da Educação. Revista da Diretoria Regional.SAERJ - 2010 / Universidade Federal de Juiz de Fora, Faculdade de Educação, CAEd. Juiz de Fora, v. 2, s/n, jan/dez. 2010.

SANT'ANA, I. M. ; SANT'ANA V. M. Recursos Educacionais para o ensino: quando e por quê? Petrópolis, RJ: Vozes, 2004.118 p.

SOUZA, V. M. ; MARIANI, V. C . Um breve relato do desenvolvimento do conceito de função. In: V EDUCERE, 2005, Curitiba. Anais... Curitiba. 2005. p. 1-12. Disponível em: < http://www.pucpr.br/ev entos/educere/educere2005/anaisEvento/documentos/com/TCCI021.pdf>. Acesso em: 11 set. 2013.

VÁZQUEZ, S.; REY, G.; BOUBÉE, C.; “El concepto de función a través de la Historia”, Revista Iberoamericana de Educación Matemática; v. 4 , n.16, p. 141-151, dez. 2008.

Submetido em Outubro de 2013. Aprovado em Março de 2014. 